\title{
Frente al imposible espejo de la naturaleza: Rorty y Habermas
}

\author{
In front of the impossible nature's mirror: \\ Rorty and Habermas
}

\begin{abstract}
Resumen: Este artículo responde sobre todo a un ánimo de difusión. Me propongo ofrecer algunas de las claves del tipo de debate filosófico que, hasta hace no demasiados años, sostenían Richard Rorty y Jürgen Habermas. Sugeriré, en aras de este propósito, una suerte de ruta para pensar dicha controversia, de tal manera que pueda evidenciarse lo que aproxima a ambos filósofos hasta el punto de también hacer posible la distancia entre ellos; y, desde ésta, las críticas que se dirigen mutuamente. En tal tesitura sostendré que la encrucijada del debate remite al problema de la posible distinción entre las nociones de verdad y justificación.
\end{abstract}

Palabras clave: Lenguaje, Justificación, Habermas, Rorty, Verdad.
MIGUEL FERNÁNDEZ MEMBRIVE*

\begin{abstract}
The purpose of this article is dissemination. I will present some of the key elements of the type of philosophical debate in which Richard Rorty and Jürgen Habermas engaged until relatively few years ago. To this end, I will suggest a way of reasoning through their disagreement in such a way as to evidence what brought these two philosophers together, and, at the same time caused the distance between them, which resulted in their criticism of each other. Therefore, I will propose that the crux of the debate leads back to the problem of the possible distinction between the ideas of «truth» and «justification».
\end{abstract}

Key words: Language, Justification, Habermas, Rorty, Truth.

\section{Introducción}

La discusión sostenida entre Habermas y Rorty, podría decirse que hasta fechas próximas al fallecimiento del segundo, el 8 de junio de 2007, fue y aún es un registro interesante para la filosofía contemporánea no sólo por tratarse de dos de sus principales representantes

Fecha de recepción: 07/02/2013. Fecha de aceptación: 29/07/2013.

* Miguel Fernández Membrive (membrive@iteso.mx) es Doctor en Filosofía por la Universidad de Barcelona y profesor-investigador adscrito al Centro de Formación Humana del ITESO (Universidad jesuita en Guadalajara, México), así como profesor de Historia de la filosofía contemporánea en el Departamento de Filosofía y Humanidades de la misma universidad. Su principal línea de investigación es filosofía moral y política contemporánea, con especial atención a autores como Rorty y Habermas. Dos de sus últimas publicaciones son: «Invocación del vértigo: pensar de otra manera», en Xipe Totek, Vol. XIX, N 1/31Marzo 2010. Y «Nietzsche, el reclamo de valor», en ¿Nietzsche ha muerto? México: Fundación Hombre y Mundo, Universidad Veracruzana y Universidad Autónoma de Madrid, 2009. 
en las últimas décadas, sino también por las ramificaciones explícitas o implícitas que tal intercambio de argumentos extiende por buena parte del territorio filosófico más reciente; en este sentido, es un debate que instruye más allá de sí mismo. A esto podría añadirse que Habermas y Rorty proceden de las tradiciones filosóficas más visibles de los siglo XX y XXI -de la continental, en el caso del primero, y de la tradición analítica en el caso del segundo 1 - y que tanto uno como otro han contribuido a tender puentes entre ellas más que a reivindicar distancia; de lo cual su debate mismo es un ejemplo.

En la controversia sostenida por Rorty y Habermas podría decirse que el rol de «negador» se distribuye equilibradamente entre los dos filósofos. Tanto el profesor estadounidense como su colega alemán rechazan la teoría de la verdad como correspondencia y se alejan del paradigma sujeto-objeto que tiene como principal referencia la epistemología tradicional. Pero también los dos filósofos niegan algo del otro. Rorty considera algo así como que Habermas, pese a todo, representa una versión puesta al día del fundacionismo o fundamentalismo filosófico; mientras que el filósofo alemán piensa que su coetáneo estadounidense confunde una premisa sensata con una dudosa conclusión: la premisa de que el acceso al mundo se lleva a cabo siempre desde ese horizonte sociocultural, intersubjetivo y lingüísticamente constituido que representa todo particular «mundo de la vida» ${ }^{2}$, con la conclusión de que la racionalidad simplemente se diluye en la perspectiva interna de una pluralidad de horizontes de comprensión.

Si bien ambos filósofos están interesados en la resonancia ética de su debate, podría decir desde ahora que el epicentro del mismo es su discusión en torno al problema de la verdad -de cómo concebir esta noción-, y que, con respecto a este pivote, Rorty y Habermas sólo se distancian en sus posiciones cuando arriban al siguiente cuestionamiento: si en lo que atañe a considerar válido el conocimiento disponemos ya de un concepto como el de justificación (esto es, si ya podemos decir de algo que está justificado, que tenemos evidencia o razones para sostenerlo, etc.), ¿requerimos también preservar el concepto de verdad? ¿Implica este concepto algo distinto a eso que entendemos por justificación, algo por lo cual sea efectivamente necesario preservarlo? Como veremos, Habermas defiende con más intensidad la necesidad de preservar una cierta noción de verdad que pueda distinguirse de los acuerdos o consensos fácticos particulares y aun operar como referente crítico de los mismos, lo cual informa de que la distancia entre ambos filósofos se calibra por la disposición de cada uno para responder con un sí o con un no a las preguntas de arriba.

Para desentrañar este debate en algunas de sus más interesantes claves, opté por dividir esta exposición en cuatro partes seguidas de un breve apunte a modo de conclusión. En las dos primeras hablaré de lo que ambos filósofos coinciden en negar -el espejo de la naturaleza- y de cómo se configura para ellos ese problema de la verdad y la justificación. En las dos últimas partes combinaré la presentación sintética de algunos aspectos del pensamiento de los dos filósofos con la referencia a algunas de las principales críticas que, a mi entender, se dirigen mutuamente.

1 Un extraordinario trabajo que analiza y documenta exhaustivamente- desde muy diversos ángulos- la relación entre filosofía continental y filosofía analítica, y que además sintetiza los principales tópicos de ambas tradiciones, es el de la profesora F. D’agostini, Analíticos y Continentales, Guía de la filosofía de los últimos treinta años, Madrid: Cátedra, 2000.

2 Más adelante nos referiremos con más precisión que aquí a este concepto de «mundo de la vida» en su versión habermasiana. 


\section{El imposible espejo de la naturaleza ${ }^{3}$ : verdad como correspondencia}

Como se sabe, una teoría de la verdad, en filosofía, es, grosso modo, una explicación de la naturaleza de la verdad o un esclarecimiento del significado de dicho término, lo cual muchas veces se traduce en una explicitación de las condiciones de posibilidad del mismo. En este sentido, nombres para identificar teorías de la verdad hay muchos; además de la teoría de la verdad como correspondencia, podemos hablar de teorías semánticas, coherentistas, consensuales, pragmáticas, deflacionarias, etc. Históricamente la teoría de la verdad con mayor difusión y aceptación ha sido la llamada teoría de la verdad como correspondencia; también ha sido ésta la teoría de la verdad con respecto a la cual casi todo estudioso del tema se ha sentido obligado a tomar posición. De hecho, muchas de las demás teorías de la verdad se presentan como variaciones o alternativas frente a esta concepción correspondentista.

Normalmente se dice que Aristóteles, quien estrictamente no elaboró una teoría de la verdad, sí prefiguró lo que más tarde se entendería como 'teoría de la verdad como correspondencia’. Lo hizo con su afirmación- citada más de veinte siglos después en el famoso artículo del también famoso lógico polaco Alfred Tarsky de que: «Decir de lo que es que no es, o de lo que no es que es, es (lo) falso, mientras que decir de lo que es que es, o de lo que no es que no es, es (lo) verdadero» ${ }^{4}$.

Tal afirmación sin duda contiene resumidamente los principales trazos de una teoría de la verdad como correspondencia. Contiene el supuesto de que la verdad es un concepto relacional, esto es, un concepto que se aplica a la relación entre dos tipos de factores; por decirlo en llano: a representaciones y a algo que no son representaciones, o a proposiciones y a algo que no son proposiciones; para eso que no son representaciones o proposiciones usualmente se han empleado términos tan variados como mundo (exterior), hechos, estados de cosas, realidades, etc. Antes del llamado «giro lingüístico» de la filosofía, el primer polo de la relación -el subjetivo, si se quiere- se expresaba en un vocabulario mucho más mentalista; por un lado, tendríamos pensamiento o conciencia y representación, y por otro -en el polo objetivo- aquello distinto a lo primero, aquello de lo cual la representación del pensamiento o de la conciencia sería representación. A partir del giro linguiístico es mucho más común pensar en una relación entre entidades lingüísticas -oraciones, enunciados o proposiciones-, por un lado, y por otro, entidades no linguiísticas, para las cuales se emplea frecuentemente el término «hecho».

Ahora bien, la verdad, de acuerdo con esta concepción, por supuesto no sólo es un concepto relacional, sino también un concepto normativo, que exige y de ser el caso expresa un tipo particular de relación: una relación de correspondencia. De tal manera que si tomamos en cuenta esto más lo dicho anteriormente, podríamos afirmar resumidamente, con John Searle, que una concepción de la verdad como correspondencia se presenta a menudo como una explicación así del término verdadero: «Un enunciado es verdadero si y sólo si corresponde a los hechos» ${ }^{5}$.

3 El título de este apartado, y también de este trabajo, hacen referencia al libro de R. Rorty Philosophy and the mirror of nature (1979), Princeton, EUA: Princeton University Press, 2009.

4 Aristóteles citado por A. Tarski en «La concepción semántica de la verdad y los fundamentos de la lingüística (1944), en Teorías de la verdad en el siglo XX (ed. Juan Antonio Nicolás y María José Frápolli), Madrid: Tecnos, 1997, p. 69.

5 J. Searle, The construction of social reality, New York: Free Press, 1995, p. 200 y s. 
Pero, por lo pronto, ¿Qué significa que un enunciado se corresponda con los hechos? (También podríamos preguntar, por supuesto, ¿qué es un hecho?) Si a lo primero respondemos que la correspondencia es un ajuste o una conformidad entre lo que se piensa y lo que es o existe, o entre lo que se dice y la realidad, tampoco adelantamos mucho en la aclaración del asunto; lo único que hacemos es nombrar de otra manera el problema, y el problema precisamente consiste en esclarecer lo que pueda significar esa exigencia de correspondencia, ajuste, conformidad, etc... Dicho de otro modo, el problema en todo caso consiste, por un lado, en explicar qué significa que las representaciones mentales o las proposiciones, que, se supone, son entidades de una determinada naturaleza, correspondan a los «hechos» o «estados de cosas», esto es, a entidades del mundo que, se supone también, son de una naturaleza distinta. Y por otro lado, el problema consiste igualmente en esclarecer cómo es que se lleva a cabo esa operación de contraste por la que resulta posible valorar qué representaciones o enunciados corresponden o no, de esa manera, a los estados de cosas. Esta última cuestión es la que resulta más importante para el tipo de rechazo que hacen tanto Habermas como Rorty de esta concepción de la verdad.

El núcleo del argumento que emplean tanto Habermas como Rorty para el rechazo de la verdad como correspondencia, según lo veo, es en lo esencial el mismo, y es aquél que pasa sobre todo por enfatizar la ubicuidad del lenguaje en lo que atañe al conocimiento del mundo, y cuyo más remoto y reputado antecedente filosófico probablemente se halle en el debate acerca de la verdad sostenido en los años sesenta entre J. L Austin -quien abrazaba una concepción correspondentista de la verdad-y P. F Strawson-quien proponía eliminar tal concepción ${ }^{6}$. Desde entonces, con sus propias variantes, igualmente otros filósofos han recurrido a este argumento para rechazar en algún sentido a la teoría de la correspondencia. La esencia del argumento es que la operación sobrentendida en la concepción correspondentista, aquella en la cual se supone que entidades de naturaleza diferente -por un lado, las proposiciones, y por otro, los estados de cosas o hechos no lingüísticos- serían contrastadas con el propósito de calibrar su grado de ajuste o desajuste, resultaría inviable para seres que sólo pueden identificar el mundo lingüísticamente, para seres que, digamos, no pueden exiliarse de su propio lenguaje -ni, si se quiere, de su propia experiencia- para saber qué es o cómo es eso que hay más allá del mismo. Tal operación de contraste requeriría, en todo caso, el tipo de perspectiva «externalista», neutral y sobre todo imposible a la que otro filósofo contemporáneo, Hilary Putnam, se ha referido como el «Ojo de Dios» 7 .

Con este argumento en mente, es que Habermas afirma lo siguiente en su famoso artículo de 1972, «Teorías de la verdad»:

«La teoría de la verdad como correspondencia trata en vano de romper el ámbito de la lógica del lenguaje, que es el único donde cabe aclarar la validez de los actos de habla» ${ }^{8}$.

6 Cfr. J. L Austin, «Truth» (1950), y P.F Strawson, «Truth» (1950), en G. Pitcher, Truth, Englewood Cliffs, 1964 (la traducción al castellano de ambos ensayos puede también encontrarse en la edición preparada por José Antonio Nicolás y María José Frápolli: Teorías de la verdad en el siglo XX, Op. cit.).

7 O como también dice Putnam: «la visión de la verdad del No-Ojo-, la verdad como algo totalmente independiente de los observadores». Cfr. H. Putnam, Razón, Verdad e historia, Madrid: Tecnos, 1988, p. 59 y s.

8 J. Habermas, «Teorías de la verdad», en Teorías de la verdad del siglo XX, Op. cit., p. 550. Habermas hace también explícito el argumento de la ubicuidad del lenguaje en «Verdad y justificación. El giro pragmático de Rorty», en Verdad y Justificación, Madrid: Trotta, 2002, p. 238. 
En el caso del filósofo alemán, quizás el ejemplo de mayor repercusión de cómo abraza y combina la tesis acerca de la ubicuidad del lenguaje y de la imposibilidad de acceder a una realidad culturalmente no interpretada -tesis que considera incompatibles con la teoría de la verdad como correspondencia- es su concepto de «mundo de la vida» ${ }^{9}$ en tanto «acervo lingüísticamente organizado de supuestos de fondo, que se reproduce en forma de tradición cultural» ${ }^{10}$ y que interviene necesariamente como si se tratara de un «trascendental» en los procesos intersubjetivos de entendimiento.

Por su parte, Rorty se cuida mucho de advertir que el argumento de que no podemos hacer esa comparación entre nuestro nuestras creencias sobre el mundo y el mundo considerado como esa realidad neutra, ontológicamente independiente, debería servir para convencernos de lo absurdos que resultan muchos de los «problemas» -o pseudo- problemas-, «soluciones» -o pseudo-soluciones- y posiciones filosóficas -realismo, idealismo, escepticismo e incluso relativismo- derivados de la metáfora visual o pictórica del lenguaje y del conocimiento, esto es, de la concepción de éstos a la luz privilegiada de la noción de «representación» del mundo ${ }^{11}$. Por ello, desde la «Introducción» al primer volumen de los Philosophical papers, Rorty se refiere a su propia posición como «antirrepresentacionalista», por contraste con otras posiciones, diversas entre sí, a las que identifica como representacionalistas, y dice lo siguiente:

«Típicamente, los representacionalistas piensan que las controversias entre idealistas y realistas fueron -como lo son las existentes entre escépticos y antiescépticosdiscusiones provechosas e interesantes. Normalmente, los antirrepresentacionalistas consideran absurdos los dos tipos de controversias. Según su diagnóstico, ambos son resultado de haber sucumbido a la cautividad de una imagen, una imagen de la que ahora deberíamos liberarnos» ${ }^{12}$.

Aquí habría que evitar una confusión frecuente. Lo que Rorty quiere decir es que hacerse preguntas tan variadas como éstas: ¿Nuestras descripciones del mundo -quizás basadas en último término en la observación- corresponden a lo que el mundo es? $\mathrm{O}$, ¿no es posible que un genio maligno nos esté induciendo un sueño engañoso? O, ¿no será más bien que todo depende de la perspectiva?... equivale en realidad a participar de un mismo hechizo, de aquél que insta a formular problemas filosóficos que no pueden resolverse $y$, por ende, a imaginar

9 Aunque, por supuesto, también resulta específicamente ilustrativa su comprensión de la noción misma de «hecho» -siguiendo a Strawson en su polémica con Austin- no como una cosa o acontecimiento alinguístico del mundo, sino como un «estado de cosas» identificado lingüísticamente, enunciado en el contenido de aquellas proposiciones que una comunidad de hablantes reconoce como justificadas. Cfr., Ibid., pp. 249-251. El mismo tratamiento puede hallarse también en el tercer apartado, Verdad y objetividad, del «Epílogo» a su libro Conocimiento e interés, Madrid: Taurus, 1986.

10 J. Habermas, Observaciones sobre el concepto de acción comunicativa, en Teoría de la acción comunicativa, Complementos y Estudios Previos, México, Rei, 1993, p. 495.

11 Además de en Philosophy and the mirror of nature, puede consultarse un buen resumen de este argumento de Rorty en la introducción («Pragmatism and Philosophy») a su libro Consequences of pragmatism, Minneapolis: University of Minnesota, 1982, p. Xvii-xxi.

12 R. Rorty, «Introduction: Antirepresentationalism, ethnocentrism, and liberalism», en Objetivity, relativism and Truth, Philosophical papers, Vol. 1, Cambridge: Cambridge University Press, 1991, p. 2 (citado en la traducción castellana de Jorge Vigil Rubio: Objetividad, relativismo y verdad, Escritos Filosóficos 1, Paidós, Buenos aires, 1996, p. 17). 
soluciones que no pueden serlo; por lo menos no mientras a su vez no sea posible ese exilio del propio lenguaje del que hablábamos arriba. Por eso, según lo entiende Rorty, recomendar el abandono de esa metáfora de la «representación»-o del problema de la correspondencia de ésta con un mundo ontológicamente independiente- tampoco debería confundirse con una negación de dicha correspondencia, ya que ésta sólo podría ser la presunción de una solución a aquel problema, y por lo tanto una forma más de sucumbir al hechizo del que Rorty en todo caso aconseja liberarse.

Con lo dicho hasta aquí sólo me he limitado a identificar el principal argumento que tanto Habermas como Rorty emplean para rechazar la teoría de la verdad como correspondencia. Pero, ¿cómo se supone que afecta a la cuestión de la validez del conocimiento el reconocimiento de que la realidad que nos es accesible es siempre la realidad lingüísticamente interpretada? La afecta en el sentido de que, si las creencias u oraciones empleadas para identificar algo en el mundo físico o moral han de tener algún respaldo, este respaldo sólo podrá ser el de otras creencias u oraciones, y para éstas últimas igualmente otras, y así sucesivamente; con lo cual parecería estarse describiendo una actividad de justificación consistente en hacer coherentes unas creencias con otras, unas oraciones con otras. Habermas formula muy claramente como problema esta implicación en uno de los ensayos de su todavía reciente libro Verdad y Justificación:

«Dado que la verdad de las creencias y oraciones sólo puede fundamentarse o discutirse, a su vez, con la ayuda de otras creencias y oraciones, no podemos salirnos -en tanto que seres reflexionantes- del círculo mágico del lenguaje. Esta circunstancia sugiere un concepto antifundamentalista del conocimiento y un concepto holista de fundamentación; y parece que sólo un concepto de verdad como coherencia es compatible con ambos. Por ello resulta aconsejable aclarar primero si puede rescatarse para el concepto de verdad un sentido de validez que sea independiente del contexto» ${ }^{13}$.

\section{Verdad y justificación: el corazón del debate.}

Las últimas palabras de la cita anterior ya permiten entrever que este desenlace, digamos, coherentista, de la tematización de la verdad, no deja de ser, por alguna razón, también un tanto incómodo para Habermas; mientras que, cabe decirlo, en ningún momento lo es para Rorty. No obstante, la tesis de la ubicuidad del lenguaje (de la omnipresencia del lenguaje) y su desenlace coherentista es también lo que proyecta el problema de la validez del conocimiento sobre un trasfondo o marco de intersubjetividad; sólo en el cual, o dentro del cual, puede aspirar a cualquier tipo de solución. Es lo que expresa Habermas, citando también a Rorty entre sus palabras, en un pasaje en el que sugiere (como lo hace Rorty en Philosophy and the mirror of nature) que el concepto de «objetividad» debería entenderse como «acuerdo intersubjetivo»:

«Según la concepción mentalista (...) 'El concepto «subjetivo» es lo contrario de corresponde con lo que hay afuera' y, por tanto, significa tanto como 'es meramente

13 J. Habermas, «Corrección normativa vs verdad», en Verdad y justificación, Op. cit., p. 275. 
el producto de aquello que ocurre aquí dentro'. Según la concepción lingüística, la subjetividad de las creencias ya no se controla de manera inmediata confrontándolas con el mundo, sino mediante una coincidencia pública, alcanzada en la comunidad de comunicación: 'Una reflexión subjetiva es aquella que tendría que (...) ser dejada de lado por los otros participantes racionales en el diálogo'. Con ello, la intersubjetividad del entendimiento sustituye a la objetividad de la experiencia. La relación lenguajemundo se convierte en dependiente de la comunicación entre hablante y oyente» ${ }^{14}$.

Es esa misma idea que Rorty evoca también en otros términos, en los de anteponer la «solidaridad» a la «objetividad»; o bien, en ciertas ocasiones, de sustituir al conocimiento -entendido como el producto del contacto con una realidad no humana- por la esperanza-de un consenso amplio o más amplio que el actual ${ }^{15}$.

La tesis de la ubicuidad del lenguaje y sus implicaciones coherentistas relativas a la justificación, proyectan entonces a la cuestión de la validez del conocimiento sobre este trasfondo de intersubjetividad. ¿Pero significa también esto que cualquier acuerdo o consenso fáctico es por ello verdadero? ¿Se quiere decir que el acuerdo o consenso es lo que hace verdadero a cualquier punto de vista acerca del mundo físico o moral?

Thomas McCarthy, por supuesto con Habermas en mente, se refiere a la dificultad señalada de la siguiente manera:

«¿Cuáles son los criterios de un consenso verdadero por oposición a uno falso? Si no existen criterios fiables para decidir esta cuestión entonces la teoría del discurso de Habermas no habría hecho más que cambiar de sitio el problema de la verdad, pero sin contribuir sustancialmente a su clarificación. Además, si los criterios que sirven para distinguir un consenso fundado de un consenso ilusorio exigen una justificación discursiva, nos estamos moviendo en un círculo; y si no hay círculo, es que hemos trascendido el marco del consenso al establecer ese marco» ${ }^{16}$.

Con esto hemos llegado en realidad al corazón del debate entre Habermas y Rorty. Como adelantábamos, el punto álgido del mismo remite a la cuestión de si cabe alguna distinción relevante entre las nociones de justificación y verdad; de si una vez que se ha reconocido la importancia de la justificación intersubjetiva para juzgar la validez de nuestras pretensiones de conocimiento, sigue siendo necesario, y por supuesto necesario para significar o explicar algo distinto, el concepto de verdad.

Para dimensionar mejor lo que aquí está en juego como problema, para hacerlo más próximo, podríamos preguntarnos cosas como éstas: ¿Puede una verdad dejar de ser verdad?

14 Las comillas simples corresponden a la cita que Habermas hace de Rorty (Philosophy and the mirror of nature, p. 237) en «Verdad y justificación. El giro pragmático de Rorty», Op. cit., p. 233.

15 Estas sugerencias de Rorty están regadas por muchos de sus ensayos, pero podemos referir a tres de ellos: «Solidarity or objetivity?», «Science as Solidarity», ambos en Objetivity, Relativism and Truth, Op. cit., pp. 21-45 (pp. 39-69 de la edición castellana) y «Universality and Truth», en Rorty and his critics, (ed. Robert B. Brandom), USA: Blackwell publishing Ltd, 2000, p. 3.

16 T. McCarthy, The critical theory of Jürgen Habermas, Cambridge: The Massachusetts Institute of Technology, 1985, p. 304 (citado en la traducción castellana de Manuel Jiménez Redondo: La teoría crítica de Jürgen Habermas, Madrid, Tecnos, 2002, p. 352). 
¿O es mejor decir que, en su momento y/o contexto algo pudo considerarse justificado sin que esto también signifique, como lo sabemos hoy, que haya sido verdad? ¿Fue verdad alguna vez, por ejemplo, que la tierra era el centro del universo hasta que dejó de serlo en el siglo XVI? ¿O es preferible decir que tal proposición en otro momento y contexto, bajo ciertas condiciones de justificación entonces accesibles, llegó a considerarse válida, pero que desde hace mucho tiempo sabemos también que no era verdad? O bien, en otro tipo de ejemplo, éste de carácter moral o político: ¿nunca fue verdad que las mujeres no eran estrictamente ciudadanas, o que eran ciudadanas de segunda, sino que en todo caso se trató de un prejuicio que en otro tiempo pudo considerarse justificado por algunos o por muchos? ¿Ahora por fin hemos alcanzado la verdad acerca de la igualdad entre mujeres y varones, esa igualdad fundante de derechos y obligaciones políticos?

Lo que ilustran los ejemplos anteriores es que cuesta mucho admitir que la verdad sea una propiedad que los enunciados o proposiciones puedan perder; como si una vez verdadero, siempre verdadero; mientras que con la justificación no ocurriría lo mismo ${ }^{17}$; como si una vez justificado, no necesariamente justificado en otro momento y contexto, no necesariamente verdad. La verdad, pues, tendría que ser incondicional, no algo supeditado a tiempo y lugar, a la información recabada o a otros muchos factores; pero no así la justificación, que siempre se produce bajo ciertas condiciones, que siempre es en este sentido contingente.

Con respecto a esta cuestión emergen las diferencias entre los dos filósofos, ya que Habermas hace mucho más que Rorty -lo cual no significa que lo haga también mejorpor remediar aquello del desenlace coherentista que ya antes decíamos que le provocaba incomodidad. Sin negar esta implicación, el filósofo alemán trata, a diferencia de su colega estadounidense, de salvar en algún sentido la noción misma de incondicionalidad, en algún sentido que aún haga inteligible la tarea de enjuiciar críticamente a los diversos u opuestos acuerdos intersubjetivos, tanto fácticos como posibles; y de enjuiciarlos, por supuesto, con respecto a sus pretensiones de verdad o de racionalidad.

En lo que sigue, por ser Habermas quien acomete este programa, y por ser Rorty más bien un crítico de cualquier pretensión de incondicionalidad -tanto en epistemología como en éticay por ello también un crítico de la peculiar empresa habermasiana, resumiré según este orden el pensamiento de ambos filósofos sobre la cuestión. Primero repasaré resumidamente una noción habermasiana que engloba otros conceptos de su filosofía y que resulta indispensable a su tentativa, gracias a la cual también Habermas puede formular sus principales objeciones a Rorty; para en un segundo momento casi limitarme a señalar la contraparte, esto es, cuál es, a mi entender, el principal dardo crítico que el profesor norteamericano dirige contra la arquitectura conceptual de su colega alemán. Ambos tratamientos corresponderán, respectivamente, a la tercera y cuarta parte de mi exposición, tras las cuales concluiré la misma.

\section{Habermas: validez universal y «situación ideal de habla»}

La noción habermasiana a la que aludía arriba es la de «situación ideal de habla». Pero antes de referirme a la misma, quisiera apuntar que Habermas entiende por «discurso argumentativo», o simplemente por discurso, la forma de comunicación caracterizada por

17 H. Putnam, Razón, Verdad e historia, Op. cit., p. 64. 
la argumentación, en la que se tornan tema las pretensiones de validez que se han vuelto problemáticas y se examina si son legítimas o no» ${ }^{18}$; esto es, entiende por discurso lo mismo que podría entenderse como «práctica intersubjetiva de justificación». Y que asimismo, el filósofo alemán llama consenso a aquello que se busca mediante un discurso; de hecho, lo que en realidad entiende Habermas es que la finalidad de un discurso es restaurar un malogrado consenso previo de la comunicación.

Por otro lado, ese concepto de «pretensión de validez», que es aquello para lo cual en un discurso se ofrecerían razones en pro o en contra, significa para Habermas un tipo de oferta, normalmente implícita pero en ocasiones también explícita, que necesariamente hacemos a otros cuando nos comunicamos con ellos o cuando argumentamos ante ellos: la oferta de que éstos reconozcan o acepten como válido lo que decimos y la intención que tenemos al decir lo que decimos; cosa que, como en cualquier oferta, un oyente o interlocutor puede también aceptar o rechazar (según el filósofo alemán, nosotros hacemos cuatro tipos de pretensiones de validez en nuestros actos de habla: comprensibilidad, verdad, corrección o rectitud y veracidad, aunque normalmente enfatizamos alguna de ellas) ${ }^{19}$.

Con base en este conceptos de pretensión de validez y, desde luego, de discurso argumentativo, es que Habermas propone su noción de «situación ideal de habla»; la cual, dicho sea aquí sólo de paso, remite a lo misma que Karl-Otto Apel llama «comunidad ideal de comunicación» ${ }^{20}$. Esta noción hace referencia a ciertas condiciones ideales de argumentación que, según Habermas -y, por supuesto, también según Apel- estaría presuponiendo todo aquél que participara en un discurso argumentativo con la intención sincera de convencer o de convencerse sobre alguna pretensión de validez puesta en cuestión. En tal situación, toda pretensión de validez, propia o ajena, revela su orientación transcontextual, su carácter de pretensión de validez universal, e implica así el presupuesto de una «situación ideal de habla» ${ }^{21}$.

El argumento empleado a veces por el filósofo alemán para apuntalar esta noción de situación ideal de habla es más o menos el siguiente: nadie entra en una práctica intersubjetiva de justificación con la intención sincera de convencer o de convencerse de algo si no presupone que sólo «el mejor argumento», y nada más, decidirá el consenso sobre la validez de la pretensión que se halle en disputa. Este presupuesto sería entonces el correlato de una pretensión de validez universal en este plano del discurso argumentativo. Ahora, de ser así, todo el que toma parte en un discurso, al presuponer dicha abstracción de los argumentos, anticipa también con ello que ninguna otra circunstancia o limitación relativa al contexto particular en el que éste se realiza -o a cualquier otro contexto-, empezando, por ejemplo, por cuántos y quiénes sean los demás participantes en la práctica discursiva -y por cómo estén organizadas sus respectivas cuotas de poder o de información-, o por

18 Cfr. «Teorías de la Verdad», Op. cit., p. 548.

19 Cfr. J. Habermas, Teoría de la acción comunicativa (2 Tomos), Madrid: Trotta, 2010, p. 65 y s.

20 Cfr. K. O. Apel, Transformation der Philosophie, Frankfurt am Main: Suhrkamp Verlag, 1972.

21 Es a lo que se refiere Habermas cuando dice: «Pues a lo que la teoría de la acción comunicativa apunta es a ese momento de incondicionalidad que, con las pretensiones de validez susceptibles de crítica, viene inscrito en las condiciones mismas de los procesos de formación de consenso; en tanto que pretensiones éstas trascienden todas las limitaciones espaciales y temporales, todas las limitaciones provinciales del contexto de cada caso». Teoría de la acción comunicativa, Op. cit., p. 566. 
cuál sea el tiempo y lugar en el que ésta se inscribe, va a condicionar su resultado ${ }^{22}$. Esto ciertamente equivale a presuponer la posibilidad de validez incondicional; incondicional en tanto inmune a cualquier determinación de índole circunstancial o contingente ${ }^{23}$.

Y si fuera el caso que este presupuesto de incondicionalidad bajara, digamos, del plano ideal o contrafáctico al plano fáctico o empírico, tendría también que traducirse en esas «poco probables»-como Habermas las llama-condiciones que él mismo desglosa en varios lugares de su obra:

«... apertura al público e inclusión, participación igualitaria, inmunización frente a coacciones externas e internas, así como orientación al entendimiento de todos los participantes (es decir, expresiones sinceras) $\gg^{24}$.

Por supuesto, el filósofo alemán entiende que estas condiciones, en términos fácticos, sólo pueden alcanzarse de manera aproximada, esto es, menos o más aproximada a ese ideal presupuesto por todo aquél que argumenta y atiende sinceramente argumentos.

Si ahora nos preguntamos qué gana Habermas con la reconstrucción teórica de este presupuesto que llama «situación ideal de habla», la respuesta cae por su propio peso: gana el reconocimiento de unas condiciones de discurso y de acuerdo universales o perfectamente racionales (perfectamente adecuadas a la razón en tanto presupuestas por todos los que participan en prácticas de argumentación), mismas que pueden fungir como idea regulativa, como parámetro crítico-normativo, para calibrar el grado de racionalidad o de validez alcanzado en los diversos acuerdos vigentes ${ }^{25}$.

Lo que también ahora habría que revisar es cómo incide esto último en esa cuestión de esclarecer la distinción, de haber alguna, entre las nociones de verdad y justificación. Además de la ganancia que acabamos de destacar, ¿le permite también a Habermas su noción de una «situación ideal de habla» solucionar tal problema? En algún momento de su trayectoria intelectual Habermas pensó que sí y llegó a sostener una versión idealizadora de la noción de verdad. En la estela de una tradición de pensamiento sobre la justificación y la verdad que se remonta hasta Charles Peirce, quien ya habló de la verdad, por contraste con la mera justificación, como aquella opinión que estaría destinada a ser considerada justificada por los investigadores en un supuesto fin de la investigación, también Habermas, al lado de otros célebres contemporáneos como Apel o Putnam, propuso entender que verdadero sería aquel

22 Cfr. J. Habermas, «Verdad y justificación. El giro pragmático de Rorty», en Verdad y justificación, Op. cit., p. 249.

23 En muchas ocasiones, Habermas atribuye esta pretensión de incondicionalidad a una suerte de influencia del plano práctico de la vida sobre el plano del discurso argumentativo, ya que en el primero el saber orientador de la vida es y ha de ser asumido en actitud no falibilista; como si se tratara, de hecho, de un saber incondicional. Lo que sugiere Habermas es que esta suerte de precomprensión realista no sólo influye en esa orientación a la verdad incondicional que presupone idealmente el discurso argumentativo, sino también en la conciencia falibilista respecto de la justificación que le resulta concomitante. Cfr. Ibid., p. 252.

24 Ibid., p. 249.

25 Por eso dice Habermas en «Teorías de la verdad» (en Teorías de la verdad en el siglo XX, Op. cit., p. 591): «Un consenso racional sólo puede distinguirse, en última instancia, de un consenso engañoso por referencia a una situación ideal de habla». Cfr. también J. Habermas, Acción comunicativa y razón sin trascendencia, Barcelona: Paidós, 2002, p. 56. 
enunciado que en una «situación ideal de habla» -o en una comunidad ideal de comunicación- encontraría un acuerdo alcanzado por medios argumentativos» ${ }^{26}$. De esta manera justificación y verdad ya no serían conceptos intercambiables, pues este último término estaría reservado para lo justificado bajo condiciones epistémicas ideales, sólo para lo justificado bajo las condiciones de una hipotética situación ideal de habla.

Sin embargo, en sus textos más recientes, Habermas no defiende esta posición de la misma manera. Además de reconocer a algunas de las buenas objeciones presentadas contra los intentos de definir la verdad en términos de justificación bajo condiciones ideales ${ }^{27}$, Habermas acepta que no todas las condiciones implícitas en el presupuesto de la situación ideal de habla «mantienen conexión con capacidades humanas»-o están al alcance de decisiones humanas. Una de estas condiciones, por ejemplo, de enorme peso, sería la del tiempo- cuando, idealmente, lo que se presupone es validez perenne. Por eso el mismo Habermas dice en este tenor:

«todos los discursos reales que se desarrollan en el tiempo son limitados con respecto al futuro, [y] no podemos saber si los enunciados que hoy, incluso bajo condiciones ideales aproximativas, son racionalmente aceptables se sostendrán en el futuro frente a los intentos de refutación» ${ }^{28}$.

No obstante, y para concluir esta exposición del pensamiento de Habermas, habría que decir que el filósofo alemán no aboga por una equiparación de las nociones de verdad y justificación. Aunque admite que la primera nos es inaccesible, o dicho de otra manera, que la justificación -con sus limitaciones- no puede trascenderse cuando se trata de determinar discursivamente la validez, también entiende que ambos conceptos no deberían ser confundidos: el concepto de verdad, a diferencia del concepto de justificación, connota esa validez incondicional -que, por lo demás, parecemos asumir en todo lo que tenemos por verdadero en el plano práctico y cotidiano de la vida.

Pero además y sobre todo, Habermas piensa que la orientación a la verdad incondicional sigue siendo necesaria como el parámetro normativo -o «idea regulativa»- que permite trascender los contextos vigentes y particulares de justificación, e incluso explicar esta misma motivación. Precisamente esto, el reconocimiento de un ideal normativo y la capacidad de explicar la motivación de justificar enunciados o creencias ante públicos diferentes y cada vez mayores (la de no conformarse con las justificaciones vigentes), es lo que el filósofo alemán cree que pierde Rorty al acortar al máximo la diferencia entre verdad y justificación. Ésta, a mi modo de ver, sería a fin de cuentas la más importante crítica que Habermas hace a su colega estadounidense en el debate que mantiene con él.

26 Habermas aún sostiene esta posición en su artículo «Teorías de la verdad», Op. cit.

27 El mismo Habermas expone estas críticas en su ensayo «Verdad y justificación. El giro pragmático de Rorty», Op. cit., pp. 246-250. Por otro lado, pueden verse observaciones de Rorty a este tipo de teorías ideales en su «Response to Habermas», en Rorty and his critics, (ed. Robert B. Brandom), Op. cit., p. 60.

28 J. Habermas, «Verdad y justificación. El giro pragmático de Rorty», Op. cit., p. 250. 


\section{Rorty vs Habermas}

En efecto, reducir al máximo la diferencia entre verdad y justificación, hasta el punto de volverla irreconocible, es lo que en resumen puede decirse que promueve el filósofo estadounidense después de que ha negado, como Habermas, la teoría de la verdad como correspondencia; $y$, antes o a la par de esto, a la concepción del conocimiento a la luz de la noción de «representación».

Pero tampoco es que por ello Rorty renuncie a interpretar bajo cualquier aspecto el carácter normativo del conocimiento o de la racionalidad. Más bien a cambio de la concepción representacionalista nuestro autor suele remitir a la tradición pragmatista clásica-sobre todo a Dewey y a James-y a la que él llama «neo»-que comprehendería a filósofos como Quine, Sellars, Goodman, Putnam y Donald Davidson-29, en la cual también se incluye él mismo como un orgulloso heredero del pragmatismo clásico, y en este sentido presenta muchas y variadas tesis de connotación normativa en nombre del pragmatismo o bajo el rótulo «nosotros los pragmatistas»; aunque, en efecto, parece que el principal o más amplio rasgo de su propio neopragmatismo, y el rasgo que a su vez cree detectar en aquellos «pragmatistas» que le merecen mayor admiración, es su acusado antirrepresentacionalismo, esto es, su voluntad de sustituir la noción de «representación del mundo» por esa concepción neodarwinista del conocimiento y del lenguaje -a la que antes veíamos que Habermas hacía alusión- que exhorta a pensar en éstos como en instrumentos de adaptación a un entorno determinado, como en herramientas para tratar o habérselas eficazmente con el mundo ${ }^{30}$. Rorty lo dice así:

«Los pragmatistas insisten en modos no oculares, no representacionales de describir la percepción sensorial, el pensamiento y el lenguaje, porque quisieran romper con la distinción entre conocer cosas y usarlas. Parten de la afirmación de Bacon de que el conocimiento es poder, y proceden a afirmar que el poder es todo en lo que consiste el conocimiento, que una afirmación de que se sabe $\mathrm{X}$ es una afirmación de que se está en condiciones de hacer algo con $\mathrm{X}$ o a $\mathrm{X}$, de poner a $\mathrm{X}$ en relación con algo más» ${ }^{31}$.

Sin duda que, por referencia a ese criterio del arreglárselas con los objetos -a veces llamado eficacia o utilidad-, Rorty tampoco promueve la idea de que todas las herramientas sean equiparables o igualmente eficaces cuando se trata de alcanzar un mismo propósito, y éste es el sentido -el único- de normatividad que preserva su concepción pragmatista o antirrepresentacionalista de la racionalidad. Ahora, lo que el filósofo estadounidense también sugiere es que toda duda acerca de cuáles sean las mejores creencias-herramientas para

29 En su «Truth without correspondence to reality», en Philosophy and social hope (London: Penguin Books, 1999, p. 35), Rorty señala las dos principales diferencias que percibe entre los pragmatistas clásicos y los neopragmatistas. La primera tiene que ver con la asunción del giro lingüístico en éstos últimos, esto es, «con hablar de la experiencia, como lo hicieron James y Dewey, y hablar del lenguaje, como lo hacen Quine y Davidson»; la segunda diferencia dice Rorty que tiene que ver con la suposición de que hay algo llamado el método científico, cuyo empleo incrementa la posibilidad de que nuestras creencias devengan verdaderas».

30 En su ensayo «Pragmatism, Davidson and truth», en Objetivity, relativism and truth, Philosophical papers, Vol. 1, Op. cit., p. 132 (p. 181 de la edición castellana), Rorty dice que el pragmatismo «consiste en sentido muy amplio en la tesis de que sólo podemos evitar pseudoproblemas si desechamos la idea de correspondencia con la realidad».

31 R. Rorty, «A world without subtances or essences», en Philosophy and social hope, Op. cit., p. 50. 
tratar con el mundo es también algo que sólo puede decidirse mediante la suerte de ensayo pragmático que representa para él la práctica de la justificación, esto es, la práctica consistente en poner a una cosa en un contexto provechoso para habérselas con ella, y en la cual este contexto constituye la red de relaciones coherentes en la que dicha cosa -de la que se habla- es colocada respecto de otras. De aquí que a Rorty le guste citar aquel lugar en el que William James afirma que «lo verdadero es el nombre de cualquier cosa que demuestre ser buena como creencia, y buena, además, por razones definidas y asignables» ${ }^{32}$. Y que lo haga para interpretar que con ello James reivindicaba la justificación como lo único o todo lo que nos es posible entender tanto acerca de la verdad como de la bondad o rectitud.

Con base en este abordaje pragmatista del problema de la validez, el filósofo estadounidense considera que la persistencia del término verdad, o si se quiere, del supuesto de una distinción entre verdad y justificación, sólo tendría sentido por referencia a una función relevante, que es la que Rorty -y otros, entre ellos Habermas- llama uso precautorio del predicado verdadero. Al margen de este uso precautorio, piensa Rorty que emplear el término verdad para referirse a lo que cada quien ha podido considerar justificado, es hacerle a eso mismo un cumplido ${ }^{33}$ sin demasiada importancia. ¿En qué consiste, pues, ese uso precautorio del término verdad -o del adjetivo verdadero- que, a diferencia del autocumplido, sí podría ser relevante? En algo muy simple: el término verdad, según Rorty, aún nos puede servir para recordarnos la posibilidad de que eso que hoy consideramos justificado, otros o nosotros mismos no lo consideremos de la misma manera en un tiempo futuro ${ }^{34}$ : «el único sentido que tiene contrastar lo verdadero con lo meramente justificado es contrastar un futuro posible con el presente actual» ${ }^{35}$.

Después de ésta, que es siempre la posición rortyana de referencia sobre el problema de la verdad y la justificación, el papel de Rorty en el debate con Habermas se podría decir que es sobre todo crítico; por lo mismo, paso ahora directamente a exponer las dos principales críticas que, a mi entender, el norteamericano le plantea a su colega alemán. Con esto nos aproximaremos también a la conclusión.

El ataque de éste a Habermas se dirige, como pudiera esperarse, contra el recurso fundamental del pensador alemán para salvar de alguna manera ese sentido de incondicionalidad que tradicionalmente se asocia con la noción de verdad (y no simplemente con la noción de justificación intersubjetiva): se dirige contra aquella idea habermasiana de pretensión de validez orientada a la universalidad o a la incondicionalidad; o mejor dicho, orientada a una universalidad que en realidad se entiende como un presupuesto de incondicionalidad; de aquél mismo que, como vimos, Habermas reconoce bajo el nombre de «situación ideal de habla».

32 W. James («Pragmatism and the meaning of truth») citado por Rorty en su ensayo «Is truth a goal of inquriy?», en Truth and progress, Philosophical papers, Vol. 3, EUA: Cambridge University Press, 1998, p. 21 (Trad. al cast. de Ángel Manuel Faerna García Bermejo: Verdad y Progreso, Escritos Filosóficos 1, Paidós, Barcelona, 2000, p. 33). La cita corresponde a esta última edición castellana.

33 Cfr. R. Rorty, «Solidarity or objetivity», Op. cit., p. 24 (p. 43 de la edición castellana).

34 En su mismo ensayo «Solidarity or objetivity?», Ibid., p. 23 (p. 41 de la edición castellana), dice Rorty: «Desde un punto de vista pragmatista, decir que aquello que es racional para nosotros puede no ser verdadero, es simplemente decir que alguien puede salir con una idea mejor. También es decir que siempre hay lugar para una creencia mejor, pues pueden surgir nuevas pruebas, o nuevas hipótesis, o todo un nuevo vocabulario».

35 R. Rorty, «Truth without correspondence to reality», Op. cit., p. 39. Esta frase aparece en cursivas en el texto original. 
Lo que Rorty argumenta contra Habermas es, en primer lugar, que lo habitual es no pretender ese tipo de validez ni presuponer esa «situación ideal de habla»; y en segundo lugar, que aunque fuera éste el caso, nadie tendría buenas razones para pretender o presuponer tal cosa.

En cuanto a esto último, en realidad Rorty emplea aquí aquel mismo argumento que el propio Habermas reconocía como válido, en cuanto a que nadie podría anticipar con seguridad lo que en un tiempo futuro -ni siquiera bajo condiciones de justificación aproximativamente ideales- se tendrá por justificado. Pero el filósofo norteamericano no sólo emplea este argumento considerando este factor temporal, sino que lo refiere, de manera más amplia, a la noción de «nuevo público». Para Rorty, todo aquél que pretendiera ser capaz de justificar ante todo nuevo público, real y posible -digamos, ante cualquier hombre-, aquello que de momento sólo ha justificado ante un público local o familiar, sería como un imaginario campeón de pueblo que, «henchido por la victoria... predice poder vencer a cualquier retador, en cualquier momento, en cualquier lugar». Como dice él: «Quizá pueda, pero no tiene buenas razones para pensarlo, y sería inútil para él hacer esa afirmación» ${ }^{36}$. Sería inútil porque el hecho de hacer tal presunción de ninguna manera le aseguraría su buena suerte. Con este argumento, pues, Rorty niega que sea sensata esa idea habermasiana de pretender una validez incondicional o de presuponer una «situación ideal de habla».

Pero Rorty de entrada piensa, y esto es lo que nos remite a la que, yo diría, es su más importante crítica a Habermas, que para nada es «necesario ser como ese campeón del pueblo o del barrio, que el alarde de este campeón no es un elemento intrínseco o estructural de nuestra racionalidad discursiva; es más, que ni siquiera es tan habitual. Lo que, en cambio, y atenidos a la experiencia, dice Rorty que sí parece ser mucho más habitual es que «el único ideal presupuesto en el discurso es el de justificar nuestras creencias ante un público competente» ${ }^{37}$.

Este público competente no sería igual a todo público, real y posible. Un público competente sería sólo aquel público que un determinado sujeto, o una determinada sociedad (podríamos pensar, por ejemplo, en cierta comunidad científica, o simplemente en cierta comunidad moral o política), puede percibir, por lo que sea, como una audiencia relevante a efectos de querer convencerla sobre algo o de estar dispuesto a ser convencido por ella ${ }^{38}$. Según el norteamericano, una vez que alguien se siente justificado ante aquel o aquellos públicos que considera relevantes, lo normal es que no apunte más allá de ellos, que no haga presunciones con respecto a otros, y menos con respecto a públicos imaginarios, aún inexistentes.

Con este último argumento también Rorty piensa que se inmuniza frente a una famosa acusación que tanto Habermas como Apel suelen dirigir a quienes rechazan aquellos presupuestos que ellos reconocen a la base de la racionalidad comunicativa. A tal acusación se le conoce con el nombre técnico de «autocontradicción performativa», y fundamentalmente consiste en señalar que no se puede negar el presupuesto de una situación ideal de habla

36 R. Rorty, «Response to Habermas», Op. cit., p. 56.

37 R. Rorty, «Universality and truth», Op. cit., p. 9. Las cursivas corresponden al texto original.

38 A esto se refiere Rorty cuando dice: «los seres humanos se dividen, por lo común, en comunidades de justificación mutuamente sospechosas (no mutuamente ininteligibles) -grupos mutuamente excluyentes- que dependen de la presencia o ausencia de una coincidencia suficiente en la creencia y el deseo». Ibid., p. 15. 
sin afirmarlo al mismo tiempo, esto es, sin presuponerlo. A propósito de esto, y teniendo en cuenta el argumento recién repasado en cuanto a que lo normal es ser selectivos con respecto a la motivación de persuadir a otros y de ser persuadidos por ellos, es que señala Rorty:

«(...) la noción de 'presuposición', cuando se extiende a creencias que aquel que presupone niega rotundamente, se vuelve difícil de distinguir de la noción de 'redescripción de la persona A en términos de la persona B'. Si A puede explicar lo que está haciendo y por qué lo está haciendo en sus propios términos, ¿qué derecho tiene B para seguir diciendo: No, lo que A realmente está haciendo es...? ?» ${ }^{39}$.

Pero, desde luego, Rorty sobrentiende que este público competente o relevante, puede ser menos o más amplio, menos o más inclusivo, dependiendo de las disposiciones y hábitos de los individuos y de las sociedades. De aquí que el norteamericano todavía extienda su argumento -al que ahora podríamos llamar etnocéntrico- hasta el punto de permitirse entender a la luz del mismo el afán inclusivista del propio Habermas. Rorty se permite entenderlo a esta luz en la medida en que no ve en tal afán inclusivista la expresión, o una expresión más - la de la filosofía habermasiana, en este caso- de esa supuesta orientación a la incondicionalidad que sería intrínseca a la razón comunicativa y discursiva, sino tan solo la consigna de un hábito contingente, forjado y desarrollado sobre todo en la estela de esa tradición particular, ilustrada y democrático-liberal, que él entiende que comparte con Habermas ${ }^{40}$. En pocas palabras: Rorty termina por hacer una lectura historicista o contextualista de la propia filosofía habermasiana, de la cual valora el conato inclusivista pero no la presunción que apareja con éste de estar reconstruyendo con su filosofía una estructura neutral de racionalidad.

Con este recorrido, considero más o menos cumplido mi propósito principal de difundir algunas de las claves del debate entre ambos pensadores. Por supuesto que un examen cuidadoso de los argumentos de uno y otro como para poder formular una hipótesis suficientemente persuasiva sobre el triunfador del mismo, exigiría mucho más espacio del aquí dedicado. De cualquier manera me gustaría concluir con la cuasi-broma de que si Rorty realmente no pretende una validez incondicional en los argumentos que emplea contra Habermas (si no se ve a sí mismo como ese campeón del pueblo), y si yo tampoco la he pretendido al exponer algunas claves del debate entre ambos pensadores, entonces probablemente el norteamericano gana la discusión, ya que con ello estaría demostrándose que la filosofía puede autocomprenderse como una conversación -entre otras- en la que no se aspira a la validez incondicional; aunque tampoco ésta pueda ser una tesis incondicionalmente válida.

\section{Bibliografía citada}
F. D’agostini, Analíticos y Continentales, Guía de la filosofía de los últimos treinta años, Madrid: Cátedra, 2000.
H. Putnam, Razón, Verdad e historia, Madrid: Tecnos, 1988.

39 Ibid., p. 10.

40 Ibid., p. 17. 
J. Habermas:

- Conocimiento e interés, Madrid: Taurus, 1986.

- Teoría de la acción comunicativa. Racionalidad de la acción y racionalización social -

Tomo 1. Crítica de la razón funcionalista-Tomo 2-, Madrid: Trotta, 2010.

- Teoría de la acción comunicativa, Complementos y Estudios Previos, México: Rei, 1993.

- «Teorías de la verdad».

- Verdad y Justificación, Madrid: Trotta, 2002.

- Juan Antonio Nicolás y María José Frápolli, ed., Teorías de la verdad en el siglo XX (ed.), Madrid: Tecnos, 1997.

- J. Searle, The construction of social reality, New York: Free Press, 1995.

K. O. Apel, Transformation der Philosophie, Frankfurt am Main: Suhrkamp Verlag, 1972.

R. Rorty:

- Consequences of pragmatism, Minneapolis: University of Minnesota, 1982.

- Objetivity, relativism and Truth, Philosophical papers, Vol. 1, Cambridge: Cambridge University Press, 1991 (Trad. al cast. de Jorge Vigil Rubio: Objetividad, relativismo y verdad, Escritos Filosóficos 1, Buenos aires: Paidós, 1996).

- Philosophy and social hope, London: Penguin Books, 1999.

- Philosophy and the mirror of nature (1979), Princeton, EUA: Princeton University, 2009.

- Truth and progress, Philosophical papers, Vol. 3, EUA: Cambridge University Press, 1998

(Trad. al cast. de Ángel Manuel Faerna García Bermejo: Verdad y Progreso, Escritos Filosóficos 1, Barcelona: Paidós, 2000).

- Robert B. Brandom, ed., Rorty and his critics, (ed.), USA: Blackwell publishing Ltd, 2000.

- Thomas McCarthy, La teoría crítica de Jürgen Habermas, Madrid: Tecnos, 2002. 